\title{
Technology Transfer, Anthropotechnology and Sustainable Development: How Do the Themes Relate?
}

\author{
Alana Corsi ${ }^{1^{*}}$, João Luiz Kovaleski ${ }^{1}$, Regina Negri Pagani ${ }^{1}$
}

\begin{abstract}
This article aims to develop a relationship between the themes technology transfer, sustainable development and anthropotechnology. For this, a systematic literature review was carried out, using the Methodi Ordinatio methodology, resulting in a portfolio of articles with scientific relevance, which was a source for data collection and analysis. As a result, it was observed that the three themes are related, generating benefits, since, based on anthropotechnology, some barriers, such as human and lack of adaptation, can be anticipated and dealt with, allowing the transfer of technology to occur effectively. In addition, anthropotechnology generates social benefits, by facilitating technological development adapted to the population receiving the technology. Technology transfer, in turn, is a means of implementing sustainable development. Thus, aligning your goals; flow and technology with sustainable objectives, will promote beneficial results not only for the economic, but also environmental and social axis.
\end{abstract}

Keywords: Technology Transfer; Anthropotechnology; Sustainable Development.

Submitted: April 29 $9^{\text {th }}, 2021 /$ Approved: December $28^{\text {th }}, 2021$

\section{Introduction}

Sustainable development has been the focus of several actions whether through the United Nations (UN); by the population; governments, with incentives and laws that promote economically viable growth, considering the burden on the environment, but also considering the impacts on society. Among the actions that support sustainable development, there are the Sustainable Development Goals (SDG), with 17 goals for until 2030 (UN, 2015).

In addition to the SDGs encouraging actions that would benefit the Triple Bottom Line (TBL), which represents the need to consider, equally, three axes, social, environmental and economic, in order to make commercial and political decisions (Elkington, 1997), it also presents ways for these actions to be facilitated and implemented, as a financial incentive; education; technology transfer and scientific cooperation (UN, 2015).

Technology transfer is a process of diffusing technologies and knowledge between two parts, whether industries, institutions, individuals (da Silva et al., 2018), that is, from the developer to a recipient. The process takes place guided by the objectives of the parties (Ismail et al., 2018). However, according to Corsi et al. (2020; 2021a; 2021b), for the transfer process to promote sustainable development, it must align both its objectives, such as flow and technology, with the objectives of sustainable development.
According to Pagani et al. (2016), the technology transfer process is complex, so it is natural for barriers to arise, influencing its effectiveness. According to the anthropotechnological approach, one of the barriers that technology transfer faces is the lack of adaptation of the technology to the receiver's location. In addition, it is necessary to adapt both to physical conditions, but also to cultural, historical, and also to social conditions, of human resources (Wisner, 1992; 1994; dos Santos et al., 1997).

Thus, it is observed that there is a beneficial relationship when relating technology transfer, sustainable development and anthropotechnology, however, this relationship is not explored in the literature. Thus, this article aims to develop a relationship between these three themes. For that, a systematic literature review will be carried out, using the Methodi Ordinatio methodology, allowing to create a portfolio of articles, which will be used to carry out a content analysis, allowing to fulfill the objective.

\section{Theoretical Background}

\subsection{Technology Transfer}

The technology transfer terminology has several definitions, according to Table 1.

(1) Universidade Tecnológica Federal do Paraná

*Corresponding author: alanacorsi@alunos.utfpr.edu.br 
Table 1. Technology transfer definitions

\begin{tabular}{ll}
\hline AUTHORS & DEFINITIONS \\
\hline Reddy and Zhao (1990) & Transfer of know-how between two organizations \\
\hline Souder, Nashar and Padmanabhan (1990) & Management process of transfer from one part to another \\
\hline Winebrake (1992) & $\begin{array}{l}\text { Process in which technology, information and/or knowledge, developed in an organization, by a speci- } \\
\text { fic institution, guided by the parties' objectives, is applied and used in another organization }\end{array}$ \\
\hline Buratti and Penco (2001) & $\begin{array}{l}\text { Unidirectional process, which goes from a donor to a recipient, in which the receiving company recei- } \\
\text { ves a technology (hardware or physical product) that it has not developed through contracts, patents, } \\
\text { licenses and other modes }\end{array}$ \\
\hline Rogers et al. (2001) & $\begin{array}{l}\text { Process of moving technological innovations, through some transfer mechanism channel, from an } \\
\text { individual or organization to another }\end{array}$ \\
\hline Günsel (2015) & $\begin{array}{l}\text { Flow of technology from one organization to another, which can be between companies, universities, } \\
\text { and organizations, from one country to another }\end{array}$ \\
\hline Yoon and Han (2017) & $\begin{array}{l}\text { The transfer of a technology developed by a specific group or institution, to another group or institu- } \\
\text { tion, and may refer to the commercialization of technologies, comprising the movement of tangible } \\
\text { and intangible assets }\end{array}$ \\
\hline Ismail, Hamzah and Bebenroth (2018) & $\begin{array}{l}\text { Process of distributing technologies from their place of origin to more people and places, being in- } \\
\text { fluenced by the characteristics of the information }\end{array}$ \\
\hline
\end{tabular}

Source: Authors (2021)

According to the definitions for technology transfer, it can be seen that there are different ways of approaching the technology. The technology to be transferred can be presented as a physical item, as tools and equipment (Buratti \& Penco, 2001), or as the information that must be acquired when using the equipment or hardware, the know how (Reddy \& Zhao, 1990; Wahab et al., 2012). According to OECD (1990) the diffusion of international technology can be through capital-embodied technology, represented by machines and equipment; human-embodied technology, represented by people; and disembodied technology, represented by the transfer of technical knowledge, expertise and know-how (Papaconstantinou et al., 1998). However, most scholars approach it as the combination of the tangible and intangible components; hardware and software; products / processes and know-how (Grosse, 1996; Li-Hua, 2006; da Silva et al., 2018).

Gopalakrishnan and Santoro (2004) sought to differentiate knowledge and technology, concluding that knowledge is less transferable than technology, being subjective, more tacit, amorphous, containing elements of human judgment, making it less reliable, theoretical and conceptual (Ismail et al., 2018). Technology, on the other hand, tends to be more specific, tangible, and less subjective, being more transferable than knowledge (Gopalakrishnan \& Santoro, 2004). On the other hand, for Bozeman (2000), knowledge is inherent to technology, that is, when technology diffuses, knowledge is transferred together.

Thus, technology transfer is a process guided by the objectives of the parties involved (Winebrake, 1992; Autio \& Laamanen, 1995), which is based on the distribution of technologies from their place of origin to other places or people (Ismail et al., 2018), with the technology covering physical components, but also the knowledge and know-how necessary for its implementation.

The technology transfer process can also present different combinations between technology provider and receiver, as for Autio and Laamanen (1995), who mention the Technology Transfer flows between University and Industry; Federal agencies and Industry; Research and Industry Institute; Federal laboratory and Industry; United States Institute and Japanese Companies, and Public Sector for Energy and Industry. Rogers et al. (2001), on the other hand, address the transfer between national research and development (R\&D) laboratories and universities. Pagani et al. (2016), in turn, create a scheme of possible combinations, according to Table 2 .

Table 2. Final search in databases.

\begin{tabular}{|c|c|c|}
\hline CATEGORIES & SUPPLIERS & RECEIVERS \\
\hline $\begin{array}{l}\text { From knowledge-based institution to Institu- } \\
\text { tion for commercial purposes }\end{array}$ & Universities; research laboratories and institutions & Industries and Small and Medium Enterprises \\
\hline From company to company & $\begin{array}{l}\text { Located in the same country; between different coun- } \\
\text { tries or internally to the company }\end{array}$ & $\begin{array}{l}\text { Located in the same country; between different coun- } \\
\text { tries or internally to the company }\end{array}$ \\
\hline
\end{tabular}

Source: Pagani et al. (2016) 
Thus, it is observed that in addition to variations in the definition of the technology, there are also several combinations between providers and receivers of the technology.

Finally, there are different approaches to the purpose of the transfer process. Some authors address technology transfer as a way to achieve economic development, such as Salahaldeen (1995), Lin (2003) and Maskus (2003), others address it as a way to increase the productivity of organizations, such as Jaffe (1989) and Henry et al. (2009). Li-Hua (2006), in his study, concluded that knowledge transfer is positively affected with economic development. Economic growth and progress in developed and developing countries are linked to the efficiency of Technology Transfer (Lin, 2003). On the other hand, Gallagher (2006) argues that technology transfer to developing countries can be problematic, as countries often lack technological capacity, as they seek technological leapfrogging prioritizing technology transfer rather than domestic technological development.

The transfer process is costly, including costs of continuous adaptation of the receiving environment, for better use of technology, costs involved in logistics, for communication and the costs of the technology itself (Reddy \& Zhao, 1990). Maskus (2003) argues that it is the policy to reduce these costs in order to obtain a more effective process, since the process promotes industrial and economic development. Therefore, there is a need for active involvement of governments, nationally, locally and globally in order to promote transfer (Yoon \& Hyun, 2009).

According to Pagani et al. (2016), technology transfer is a complex process. Due to this complexity, it is natural that barriers and their effectiveness occur. Mulamula and Amadi-Echendu (2017) discuss the high cost of obtaining sustainable technology as one of the biggest barriers to its adoption, with policies being a way to overcome these economic barriers. Pagani et al. (2016) identified the lack of knowledge or absorption capacity, for the use of technology, of the receiving entity as a barrier to effective transfer. Finally, the lack of knowledge of the sustainable benefits of technology causes a barrier to their selection and, consequently, to their transfer (Karakosta \& Psarras, 2009).

As seen, the Technology Transfer process can present different combinations of providers, receivers, technologies, and factors that affect it (Pagani et al., 2016). When the process aims to promote sustainable development, the objectives of the transfer process, the technology and the combinations between provider and receiver, must be oriented towards the same objective, allowing to result in sustainable transfers. In addition, it is necessary to identify possible barriers to the transfer and adoption of sustainable technologies, in order to anticipate their effects and result in an effective process.

\subsection{Sustainable Development and Technology Transfer}

There are numerous definitions for sustainable development, with different interpretations (Wang, 2017), however the most widespread is sustainable development as the development that seeks to meet the needs of current generations, without interfere in the ability of future generations to meet their own needs, proposal by the Brundtland Report, in 1987. In addition, it must be considered that all generations achieve social and economic development, making conscious use of natural resources (WCED, 1987).

Thus, for sustainable development to be achieved, there is a need to consider three axes, being: social, environmental, and economic. This concept came up with Elkington (1997), who suggests that it is necessary to consider the three axes of sustainability for commercial and political decision-making, known as "Triple Bottom Line" (TBL). The TBL approach has been advocated by different scholars (Shao et al., 2011; Wang, 2017; Kirli \& Fahrioğlu, 2018).

Although it is encouraged to also approach the axes of the TBL, some studies show that there is an overvaluation of the environmental and economic axis at the expense of the social axis (Corsi et al., 2020). Sustainable development will not be achieved just by raising technical solutions, creating political regulations, or from financial instruments, but by changing the culture, the way of thinking and acting (Wang, 2017).

The action in force to achieve sustainable development is the 2030 Agenda, with the 17 Sustainable Development Goals (SDG), presenting actions and expected results for the evolution of sustainability until 2030. From the analysis of the SDGs, support for the use of sustainable technologies, as well as their transfer, science and education, and cooperation to promote sustainable development to the most vulnerable and developing countries, thus encouraging the flow of transfers from developed countries to developing countries, known as North-South transfer.

Thus, it is concluded that the transfer of technology is considered a means of implementation for sustainable development, through the dissemination of clean technologies and technological development promoted by the transfer. However, for the process to result in sustainable benefits, it must align its objectives with the objectives proposed by sustainable development, reaching not only economic, but also environmental and social development.

\subsection{Anthropotechnology}

According to Wisner (1992), every machine has its cultural element, that is, there is no technique that is the ideal solution to a problem, but the human brain that is capable of achieving an intended or not objective. According to the author, for tools to be developed and implemented effectively, it is necessary to know the characteristics of man and his limits. Based on human anthropometric, physiological and psychological data, the machine can be better adapted to the user (Wisner, 1992).

Dos Santos et al. (1997), approached that anthropotechnology is inserted in the technology transfer process as a way to adapt the technology to the context of the receiver. According to the authors, for the transfer of technology between two entities, which present different realities, it is necessary to know the characteristics of the receiving 
country through studies that contemplate the geography of the place, history, demography, culture, human resources and their productive activities. It is the adaptation of technology to the user's reality (Wisner, 1994).

In addition, another way to assist the effective transfer of technology, is by studying a reference location, where the technology is already inserted, aiming to identify the barriers and difficulties of its implementation (dos Santos et al., 1997). Without this prior knowledge, technology transfer and implementation can occur, however, the results obtained may not be satisfactory, visualized through productivity, and which can be interpreted as lack of manpower or disability.

Thus, anthropotechnology can be understood as analogous to ergonomics, and ergonomics aims to adapt the workplace to man, aiming at the productivity and health of the worker, while anthropotechnology aims to adapt the technologies to be transferred to the context of the recipient, considering geographic, economic, sociological and anthropological aspects (dos Santos et al., 1997), creating better usability conditions for this technology to be implemented effectively.

Thus, since the transfer of technology is a complex process, and several barriers to its effectiveness may arise, it is necessary to analyze the context to which the technology was developed, as well as the place to which it will be transferred, allowing to anticipate barriers and creating strategies to overcome them, corroborating the ideas provided by anthropotechnology. In addition, for the transfer to be considered sustainable, it is necessary to align the objectives of the transfer process with the objectives promoted by sustainable development.

Although it is possible to identify the relationship between the three themes, there are no studies in the literature that present this relationship, making it a research gap. Therefore, the following sections will be aimed at demonstrating the relationship between technology transfer oriented towards sustainable development and anthropotechnology.

\section{Methodological Procedures}

The bibliographic procedures adopted were divided into two stages: (3.1) Construction of the portfolio of scientific articles, which will be the source of data collections; and (3.2) Content Analysis. The two stages were covered in the following subsections.

\subsection{Building the Portfolio of Articles}

In order to relate the themes Technology Transfer, Sustainable Development and Anthropotechnology, identifying in common points of interest and objectives, a Systematic Review of Literature (SRL) was carried out, resulting in a portfolio of relevant scientific articles, which will be a source of data collection and analysis. For the construction of the article portfolio, the Methodi Ordinatio methodology was used (Pagani et al., 2015; 2017). The methodology is considered a multicriteria decision tool, since from three criteria, year of publication; impact factor; and citation number, orders the articles in scientific relevance.
Thus, for the construction of the article portfolio, the nine protocols proposed by Pagani et al. $(2015 ; 2017)$ were adopted, as shown in Figure 1 , and described below.

Figure 1. Methodological procedures.

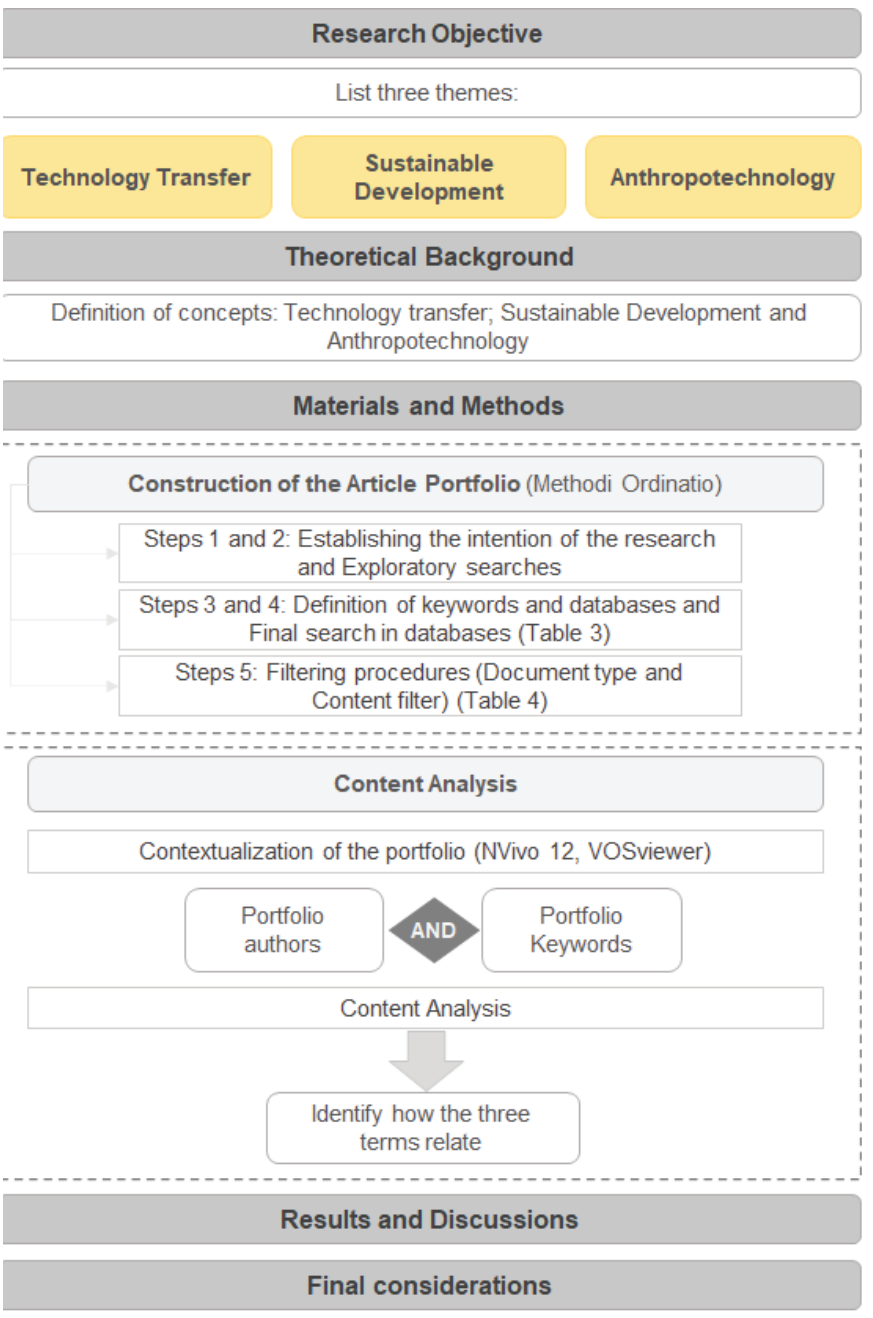

Source: Authors (2021)

As can be seen in Figure 1, Methodi Ordinatio starts with defining the intention of the research and performing exploratory searches in the databases (Steps 1 and 2), in order to identify how the returns obtained in the databases for face term and for the combination of terms.

After this preliminary search, the terms that would be used were defined, as well as their combinations in order to obtain a satisfactory return, as well as the selection of the databases with the highest return, and with that, the final search in the selected databases (Steps 3 and 4). The combinations of keywords, as well as the databases and the results of the final search were, according to Table 3. 
Table 3. Final search in databases.

\begin{tabular}{|c|c|c|}
\hline KEYWORDS COMBINATION & SCOPUS & $\begin{array}{l}\text { WEB OF } \\
\text { SCIENCE }\end{array}$ \\
\hline "anthropotechnology" AND“technology transfer" & 9 & 4 \\
\hline "anthropotechnology" AND "sustainable development" & 0 & 1 \\
\hline $\begin{array}{l}\text { "anthropotechnology" AND "technology trans- } \\
\text { fer" AND "sustainable development" }\end{array}$ & 0 & 0 \\
\hline "anthropotechnology" & 19 & 10 \\
\hline TOTAL & 43 & \\
\hline
\end{tabular}

After carrying out the final search in the databases, which resulted in an initial portfolio consisting of 43 articles, the filtering procedures (Step 5) began, aiming exclude duplicate articles; articles outside the theme; and conference articles, books, and books chapter. The results obtained were, according to Table 4.

Table 4. Filtering procedures.

\begin{tabular}{lc}
\hline FILTERING PROCEDURES & $\begin{array}{c}\text { DELETED } \\
\text { ARTICLES }\end{array}$ \\
\hline $\begin{array}{l}\text { Duplicate papers deleted } \\
\text { Deletion of articles outside the theme }\end{array}$ & 20 \\
$\begin{array}{l}\text { Exclusion by document type (conference paper; book } \\
\text { and book chapter) }\end{array}$ & 6 \\
Total articles deleted & 27 \\
The resulting number of articles in the portfolio & 13 \\
\hline
\end{tabular}

Source: Authors (2021)

From the filtering procedures, more than $70 \%$ of the articles were eliminated. Thus, the final portfolio of articles was composed of 13 articles, demonstrating the need for further studies that address this theme.

Methodi Ordinatio is a methodology that facilitates the researcher's work by building a portfolio of ordered articles, allowing the selection and prioritization of articles (Pagani et al., 2015; 2017). This functionality allows us to reduce long portfolios to more compact portfolios, but with scientific influence on the topic since it allows us to select and prioritize the articles with the greatest impact. Since the portfolio of this research was composed of a small number of articles, the following procedures (Steps 6 and 7) from Methodi Ordinatio were applied to highlight the scientific relevance of the final portfolio, based on the Impact Factor (IF), Year of publication, and Number of Citations (Ci).

So, the IF; Year of publication and Ci were collected, and the portfolio was ordered. The metric used to assess the journal's impact factor was the Scientific Journal Rankings (SJR). Zero value was adopted for journals with an unavailable SJR value. The article citation number was collected on the Google Scholar platform.
After collecting the variables, Equation (1), called InOrdinatio, was applied to the portfolio, resulting in a portfolio ordered by scientific relevance, according to Table 5 (Appendix).

InOrdinatio $=(\mathrm{IF} / 1000)+a^{\star}[10-($ ResearchYear-PublishYear $)]+$ (Ci) (1)

The elements are: IF (Impact Factor, metric used to assess the relevance of the journal); a (alpha value, metric 1 to 10 , defined by the researcher, considering the relevance of the topic's relevance), for this study, a was set to 5 , since some of the terms do not require current to be discussed; PublishYear (the year the paper was published); and $\mathrm{Ci}$ (paper citation number).

Finally, in Steps 8 and 9, after the portfolio ordering by scientific relevance, collections, and systematic analyzes of the articles were made. Thus, after building the final portfolio of articles, the procedures for collecting and analyzing data were described.

\subsection{Content Analysis}

From the construction of the scientifically relevant article portfolio, the data analysis procedures began, allowing a relationship to be built between the three main topics of this research: Technology transfer; Sustainable development and Anthropotechnology.

Initially, a bibliometric analysis of the portfolio was carried out, identifying the main authors of the portfolio and the main Keywords. For this, the VOSviewer software was used.

Finally, systematic readings of the articles were carried out in order to build a relationship between the three themes, since there are no other works in the literature that carry out this research.

After describing the methodological procedures adopted, the (4) Results and Discussions section began.

\section{Results and Discussions}

The results were demonstrated and discussed in two stages, (4.1) initially a contextualization of the portfolio of scientific articles was carried out, and, (4.2) the readings of the articles were made and then the relationship between the main themes of this research was built, thus reaching the objective of the work.

\subsection{Contextualization of the scientific articles portfolio}

The first analysis was in order to verify the main authors of the portfolio, and the metric to define the importance of the author was the number of articles that the author presents in the portfolio. To perform the analysis, the VOSviewer software was used, with its density map functionality, demonstrating both the networks of authors and the authors with the highest number of articles in the portfolio, as shown in Figure 2. 
Figure 2. Main authors.

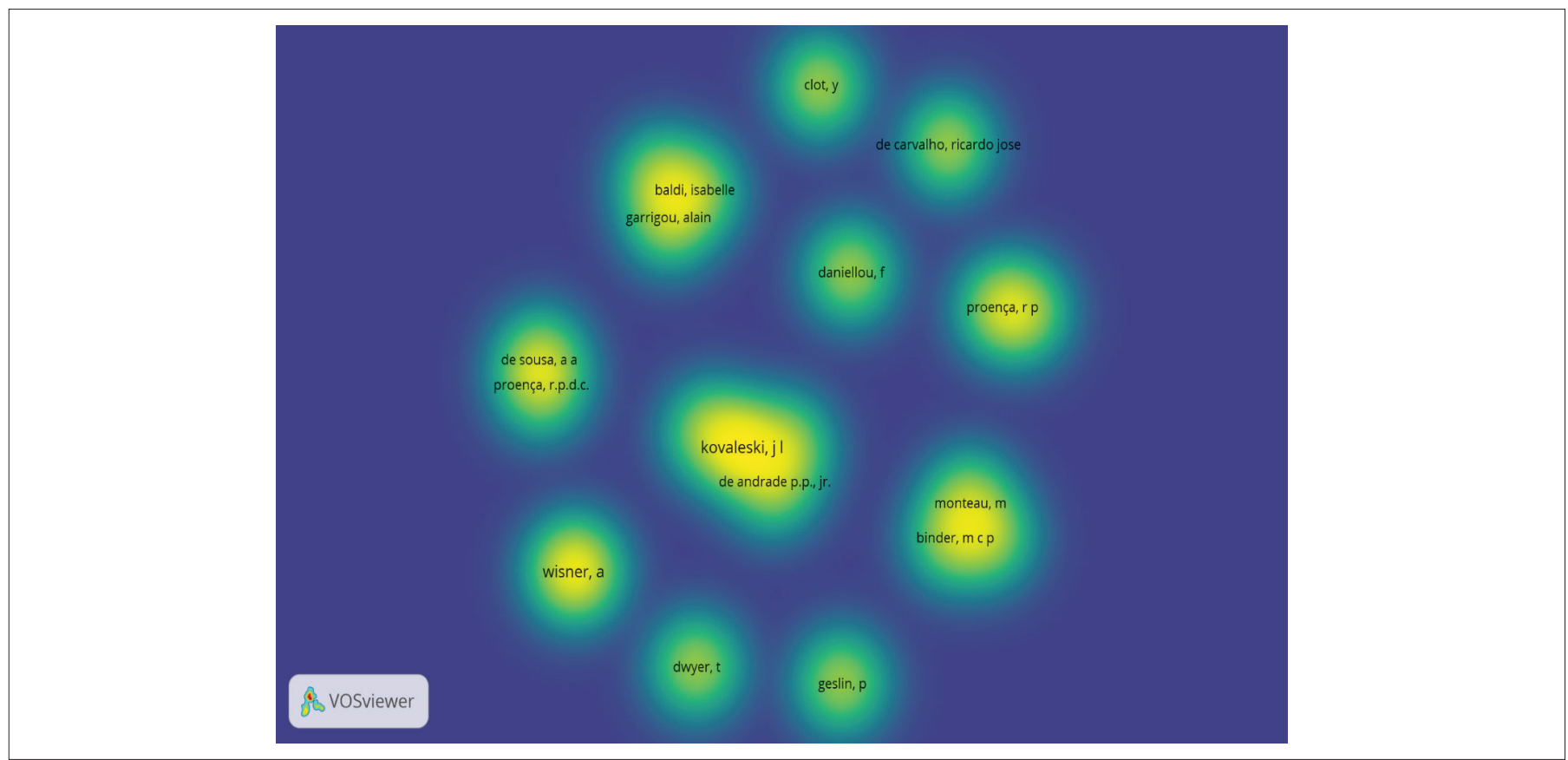

Source: Authors (2021)

From Figure 2, together with the data available in the software, it is observed that the portfolio is composed of 20 authors, who form networks to carry out the publications. The main authors of the portfolio, with the largest number of articles, are Wisner, A. and Kovaleski, J. L. with 2 articles each, representing $15 \%$ of the articles in the portfolio each. The other 18 authors present one article each. These results demonstrate that the theme is still diffuse, needing to be more deeply addressed.
Finally, the second analysis, also with the aid of the VOSviewer software, was in order to verify the main keywords mentioned in the portfolio, through the frequency in which the keyword was used. For this, the Overlay Visualization function of the software was used, which presents the distribution of the keywords over the years, demonstrating the topicality of the themes. The result obtained was, as shown in Figure 3.

Figure 3. Main keywords.

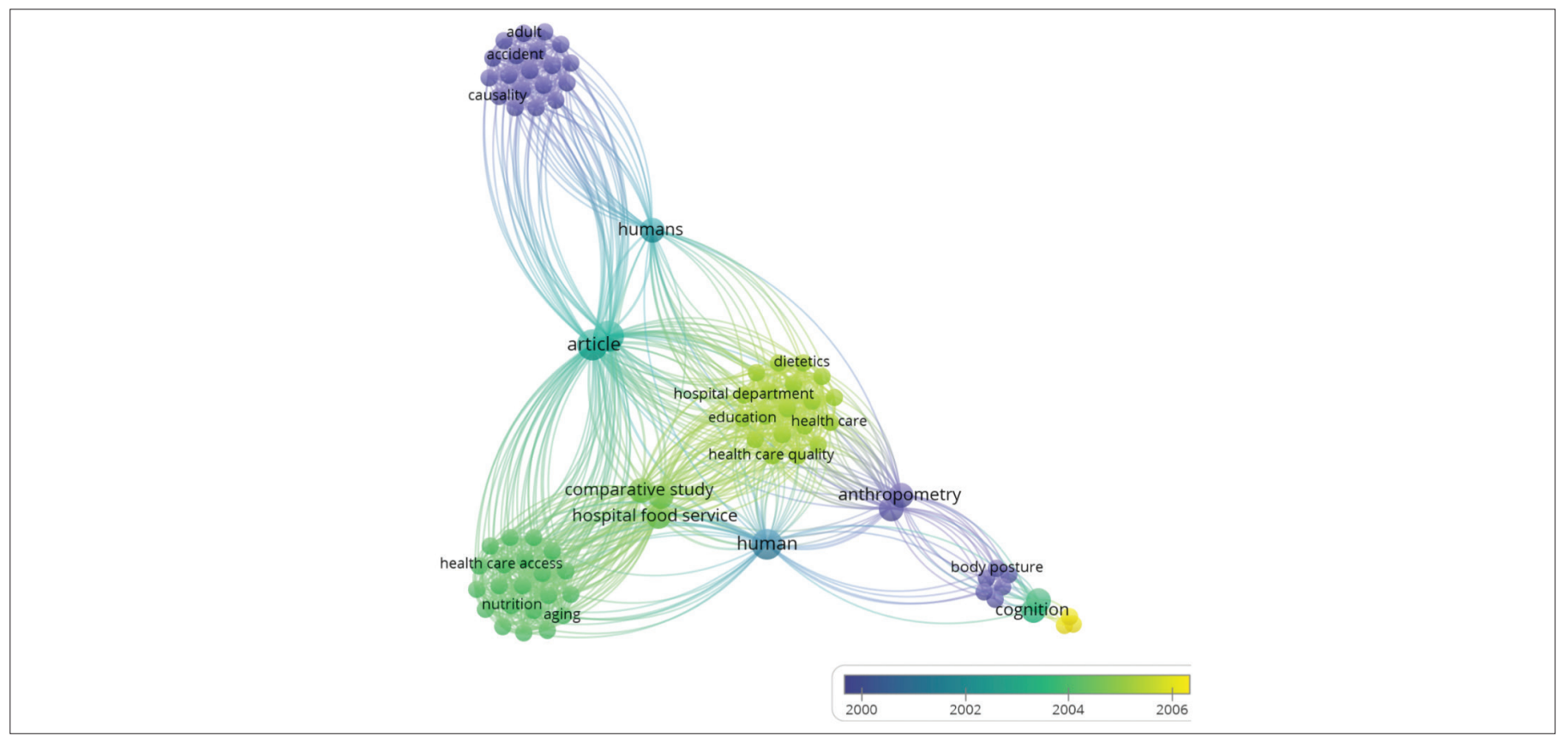

Source: Authors (2021) 
The Figure is organized in a timeline, in which the keywords in blue are those published in older articles, until reaching the yellow color, with keywords cited in more recent articles. From Figure 3, together with the data obtained in the software, it can be seen that 84 keywords were mentioned in the portfolio, and that the most frequent keyword is "human / humans", present in 5 articles in the portfolio, covering more than $35 \%$ of the portfolio, however, these are not keywords cited in more recent articles. In sequence, the most frequent keyword was "brazil", present in 3 articles (23\%). Following, "France"; "Comparative study"; "Hospital food service"; "Anthropometry" and "methodology" were recurrent, present in two articles each. Words related to anthropotechnology, technology and technology transfer were also used as a keyword, however in only one article each. The keywords cited in more recent articles are: "ergopolis"; "resilience"; "city"; "agriculture"; and others, mentioned in one article each.

In addition, from the data generated in the Overlay Visualization of the software, it is also observed that the keywords mentioned in more current articles, illustrated in yellow, are related to aspects of agriculture; anthropotechnology; city, ergopolis and resilience. Then, the keywords published in older articles, illustrated in blue, are related to anthropometry; body posture; ethnology; behavior; technological development, and others. Finally, the keywords published in articles between the most current and the oldest, that is, in the transition, illustrated in green, are related to the term human; Brazil; france; hospital food service; technology; technology transfer, and others.

From the frequency of keywords in the final portfolio of articles, it is clear that the article focuses on human social aspects, mainly represented by terms such as anthropometry; hospital services; body posture; nutrition and agriculture; accident and education. Thus, it is also concluded that among the sustainability tripod, represented by economic, environmental and social aspects, in this portfolio the social aspect is more addressed.

\subsection{Content Analysis}

After identifying the main authors and main themes covered in the scientific articles portfolio, systematic readings were carried out in order to identify the particularities of each of the themes. From the data collected it was possible to develop a relationship between the themes.

From the systematic reading of the articles, some particularities were identified, according to Table 6 .

Table 6. Characteristics of portfolio articles.

\begin{tabular}{lll}
\hline REFERENCE & EMPHASIS ON AXES & STUDY LOCATION \\
\hline Gomes and Kovaleski (2017) & Technology Transfer AND Anthropotechnology & Brazil \\
\hline Da Luz et al. (2016) & Technology Transfer AND Anthropotechnology & Brazil \\
\hline Garrigou et al. (2012) & Technology Transfer AND Anthropotechnology AND Sustainable Development & French \\
\hline Matos de Carvalho (2012) & Technology Transfer AND Anthropotechnology AND Sustainable Development & Not specified \\
\hline Daniellou (2006); Geslin (2006); Clot (2006); Dwyer (2006) & Anthropotechnology & Not specified \\
\hline De Sousa and Proença (2004; 2005) & Technology Transfer AND Anthropotechnology & Brazil and French \\
\hline Wisner (2004) & Technology Transfer AND Anthropotechnology & Not specified \\
\hline Binder et al. (1999) & Technology Transfer AND Anthropotechnology & Brazil \\
\hline Wisner (1995) & Technology Transfer AND Anthropotechnology & Not specified \\
\hline
\end{tabular}

Source: Authors (2021)

From these results, it is observed that most of the articles focus on Technology Transfer together with Anthropotechnology, representing more than $50 \%$ of the portfolio. The articles that also include Sustainable Development are fewer in number, with only two articles in the portfolio. Finally, four articles (31\%) have a central focus on discussing and conceptualizing Anthropotechnology, based on the concepts of Wisner and other theorists.

Another analysis that can be performed is when the place where the study was applied. Most studies did not focus on a particular location, representing more than $50 \%$ of the articles. However, the rest of the articles focused on two specific countries, Brazil, with three articles; France, with an article; and the study in the two countries, Brazil and France, with two articles. This demonstrates that there is a lack of research on the theme in other locations.

Finally, the collection and analysis of the content of the articles was carried out, and the results were organized in a timeline. Initially,
Binder et al. (1999) presented a study on the use of anthropotechnology to analyze the application of the causal tree method to work accidents in industrial companies in the Botucatu region, São Paulo. According to the authors, some conditions can affect the success of technology transfer, such as the weather; the skill levels and the technology that will be imported, thus requiring anthropotechnological techniques. Thus, from the application of the causal tree method, there is an improvement in the awareness of risk factors, and the preparation of personnel for a certain activity, being a social demand.

Wisner (1995) argues that before carrying out the transfer, it is necessary to study the technology in operation, allowing to identify possible flaws and correct them. In anthropotechnology, this activity is performed through the Ergonomic Work Analysis (EWA). The method also performs a study of the critical aspects of a technical system operating in the receiving country, or in a country with similar characteristics. According to the author, through the anthropotechnological approach, it is possible to trace the causes of the difficulties 
and avoid them. Thus, anthropotechnology is considered a means of improving international technology transfer (Wisner, 2004).

Wisner (2004) identified that to encourage development through transference, it is necessary to consider not only ergonomics and its concepts, but also that it is necessary to develop, test and use other knowledge, taking into account the humanities. According to De Sousa and Proença $(2004 ; 2005)$, in the anthropotechnological approach, the difficulties of technological application should not be studied only in the individual characteristics of man, but also consider all external attributes.

Thus, De Sousa and Proença $(2004 ; 2005)$ addressed the management of nutritional care in the hospital sector, through the analysis of the work of the nutritionist in Brazil and France, with the support of ergonomics and anthropotechnology. The results showed that the characteristics of the external environment directly influence work. Thus, Brazil presents a more challenging scenario, in view of the low investment; school level; purchasing power; access to consumer goods, and other factors. On the other hand, France's external factors, such as high investment in health and the organizational characteristics of the sector, among other factors, favor the execution of the work.

Still with the initiative to define and conceptualize anthropotechnology, based on Wisner and other theorists, Daniellou (2006); Geslin (2006); Clot (2006) and Dwyer (2006), carried out reviews on the theme. As Daniellou (2006), from Wisner's commitment to technology transfer, and to improving the quality of work, led him to found anthropotechnology, in order to adapt working conditions to the populations. According to reports from Wisner's experience, he comes to the conclusion that economic, cultural, administrative and historical conditions interfere with the effectiveness of a technological import, being an idea disseminated by several authors (Geslin, 2006).

Garrigou et al. (2012) discussed the use of pesticides in French viticulture. For the authors, the use of pesticides, as well as the protective equipment for their use, can be seen as a flawed technology transfer between different countries, with different contexts. The use of pesticides results in risks for both the environment and the health of the worker (Garrigou et al., 2012), being a technology not aligned with the objectives of sustainable development.

In addition, although the transfer and application of this protective equipment also occurs, those affected (workers) are not involved in the process of developing and planning their protection, resulting in inefficient equipment, therefore, posing risks to the health of these workers (Garrigou et al., 2012). Thus, the transfer of pesticide technology, as well as its protective equipment, is considered to be flawed acts, thus concluding that the anthropotechnological dimension, which studies the adaptation of technology to workers, must be considered, both for the situation of work, but also for the situation of use of the equipment.

Matos de Carvalho (2012) addresses problems in cities, such as lack of accessibility and urban mobility, whether due to lack of planning or issues of physical or informational barriers, an issue also addressed in SDG 11 "Sustainable Cities and Communities" (UN, 2015). These problems make it difficult to orient and move pedestrians, especially those with special conditions, but they also result in accidents. These problems can aggravate the flow of people and vehicles, affecting the high incidence of deaths from accidents, in addition to affecting people's quality of life and generating high maintenance costs. From the context, the author points out that there is a lack of studies that apply ergonomics in cities, encompassing their systems and people. The anthropotechnological approach, which aims to adapt transferred technologies to the conditions of users and recipients, is discussed, since it is expected to intensify the connection between people and city systems, resulting in more inclusive, intelligent and proactive cities, also benefiting the social axis.

Thus, the author introduces ergopolis as a strategy to apply ergonomic studies to cities, aiming to adapt them to human conditions, considering its characteristics, capacity and limitations, and resulting in a better quality of life for residents, bringing human aspects closer to each other. city systems (Matos de Carvalho, 2012).

Da Luz et al. (2016), in order to verify the role of anthropotechnology in the transfer of technology for the formation of spin-offs, identified that incubators support anthropotechnological approaches through consultancy and the hiring of specialists, holding meetings with the incubated in order to identify your business development needs, as well as your knowledge and technology needs. In addition, the authors identified that there is a lack of anthropotechnological approaches, which results in low productivity in the process of forming spin-offs (da Luz et al., 2016).

Gomes and Kovaleski (2017), aiming to identify how science and technology policy, as well as anthropotechnology, influence the transfer of technology, and concluded that there is an absence of transfer in policies. In addition, the authors conclude that the transfer of technology is not a process considered essential in Brazil, therefore, policies are insufficient. In conclusion, Gomes and Kovaleski (2017) affirm that it is not enough just policies supporting the transfer of technolo$\mathrm{gy}$, it is necessary to focus on how this technology is absorbed from a human perspective.

Thus, after conducting data collections and analyzes, it can be concluded that anthropotechnology assists in the success of technology transfer, demonstrating that there is a need to consider both the technological factors, the characteristics to which the technology was developed as well as the characteristics of the technology receiving site, and also consider the human and social aspects of the population that will receive this technology. From the identification of these factors, it is possible that the technology is adapted to the receiving site, increasing the chance of success.

Sustainable development enters this context from the demand for sustainable technologies and technologies that improve both the quality of life of the population, but also as a way to promote technological and economic development, considering the environmental 
benefits and impacts. From the effective transfer of technology oriented towards sustainable development, gains will occur for the three sustainable axes.

\section{Final Considerations}

This study aimed to identify the relationship between technology transfer, anthropotechnology and sustainable development. For this, a systematic literature review was carried out, using the Methodi Ordinatio methodology, which resulted in a portfolio of articles with scientific relevance. From this portfolio it was possible to list the themes, fulfilling the objective of the study.

From this work, it can be concluded that technology transfer, anthropotechnology and sustainable development are concepts that can complement each other. Anthropotechnology, defined in different ways, among them as a way to promote greater effectiveness the transfer of technology, defining that for the effective transfer to occur, it is necessary to study and analyze the conditions of the recipient, as well as the human resources of the recipient. considering cultural, historical, geographic, economic, ethnographic aspects, among others. From this, it is expected that barriers to the implementation of foreign technologies are avoided.

On the other hand, technology transfer, considered as a way to promote technological development, is one of the various means of implementing the Sustainable Development Goals (SDGs). Thus, aligning the objectives of technology transfer to the objectives of sustainable development, it is expected that benefits will occur for the sustainability, economic; social and environmental axis.

Thus, it can be concluded that although there is a lack of studies that relate the three themes, it is possible to relate them and orient them towards a common objective. In doing so, it is possible to promote sustainable development through the transfer of effective sustainable technology, which in turn is based on precepts of anthropotechnology.

The present study is limited by the fact that only articles and reviews are used, excluding the portfolio of books and conference articles. As future studies, it is suggested to define a qualitative model that comprises the three themes.

\section{References}

Autio, E., \& Laamanen, T. (1995). Measurement and evaluation of technology transfer: review of technology transfer mechanisms and indicators. International Journal of Technology Transfer Management, 10 (6), 643-664.

Binder, M. C. P., De Almeida, I. M., \& Monteau, M. (1999). Anthropotechnological analysis of industrial accidents in Brazil. Bulletin of the World Health Organization, 77(12), 1008-1016.

Bozeman, B. (2000). Technology transfer and public policy: a review of research and theory. Research Policy, v. 29, n. 4-5, p. 627-655.
Buratti, N., \& Penco, L. (2001). Assisted technology transfer to SMEs: lessons from an exemplary case. Technovation, v. 21, n. 1, p.35-43.

Corsi, A., Pagani, R. N., Kovaleski, J. L., \& da Silva, V. L. (2000). Technology transfer for sustainable development: Social impacts depicted and some other answers to a few questions. Journal of Cleaner Production, v. 245, p. 118522.

Corsi, A., de Souza, F.F., Pagani, R.N., \& Kovaleski, J. L. (2021a). Technology transfer oriented to sustainable development: proposal of a theoretical model based on barriers and opportunities. Scientometrics, 126(6), 5081-5112. https://doi.org/10.1007/s11192-021-03969-0

Corsi, A.; Barbosa, B.M.L., Pagani, R.N., Chiroli, D.M.G., \& Kovaleski, J.L. (2021b). Technology Transfer Oriented to Sustainable Development: Barriers and Opportunities. Journal of Information \& Knowledge Management 20(02):2150015. Doi: 10.1142/ S0219649221500155

Clot, Y. (2006). Alain wisner: A disputed heritage [Alain Wisner: un héritage «disputé»]. Travailler, 15(1), 185-198. https://doi. org/10.3917/trav.015.0185

Da Luz, A. A., Kovaleski, J. L., \& de Andrade P.P., J. (2016). An approach antropotecnológica in formation of Spin-offs [Uma abordagem antropotecnológica na formação de Spin-offs]. Espacios, 37(31).

Da Silva, V. L., Kovaleski, J. L., \& Pagani, R. N. (2018). Technology transfer in the supply chain oriented to industry 4.0: a literature review. Technology Analysis \& Strategic Management, v. 31, n. 5, p.546$562,2018$.

Daniellou, F. (2006). " " "Je me demanderais ce que la société attend de nous... » À propos des positions épistémologiques d"Alain Wisner]. Travailler, 15(1), 23-38. https://doi.org/10.3917/trav.015.0023

de Carvalho, R. J. (2012). ERGOPOLIS: an ergonomics approach applied to a city. Work-a Journal of Prevention Assessment \& Rehabilitation, 41(1), 6071-6078. https://doi.org/10.3233/WOR-2012-1063-6071

de Sousa, A. A., \& Proença, R. P. D. C. (2004). Technology of management of nutritional care: Recommendations to qualifying the attendance in hospital food and nutrition services [Tecnologias de gestão dos cuidados nutricionais: Recomendaç ões para qualificação do atendimento nas unidades de alimentação e nutrição hospitalares]. Revista de Nutricao, 17(4), 425-436. https://doi.org/10.1590/s141552732004000400003

Dos Santos, N., Dutra, A. R. A., Righi, C. A. R., Fialho, F. A. P., \& Proença, R. P. C. (1997). Antropotecnologia: E ergonomia dos sistemas de produção. Edutora Genesis, Curitiba.

Dwyer, T. (2006). Alain wisner and sociology : Between proximity and distance [Alain Wisner et la sociologie : entre proximité et distance]. Travailler, 15(1), 165-183. https://doi.org/10.3917/trav.015.0165 
Elkington, J. (1997). Cannibals with Forks: The Triple Bottom Line of 21st Century. Oxford: Capstone.

Gallagher, K. S. (2006). Limits to leapfrogging in energy technologies? Evidence from the Chinese automobile industry. Energy Policy, 34(4), 383-394. doi:10.1016/j.enpol.2004.06.005

Garrigou, A., Baldi, I., \& Jackson, M. (2012). The use of pesticides in French viticulture: a badly controlled technology transfer! Worka Journal of Prevention Assessment \& Rehabilitation, 41(1), 19-25. https://doi.org/10.3233/WOR-2012-0130-19

Geslin, P. (1997). Secret kinship: The ethnographer and the anthropotechnologist. Travail Humain, 60(3), 299-311.

Geslin, P. (2006). The Political and the Scientific in the Practice of Anthropotechnology [Le politique et le scientifique dans la pratique anthropotechnologique]. Travailler, 15(1), 149-163. https://doi. org/10.3917/trav.015.0149

Gomes, M. A. S., \& Kovaleski, J. L. (2017). Science and technology policy in Latin America: The political activity and the anthropotechnology in technology transfer processes [Política de Ciência e Tecnológia na América Latina: A atividade política e a antropotecnologia em processos de transferência de tecnologia]. Espacios, $38(4), 21$.

Gopalakrishnan, S., \& Santoro, M.d. (2004). Distinguishing Between Knowledge Transfer and Technology Transfer Activities: The Role of Key Organizational Factors. Ieee Transactions On Engineering Management, v. 51, n. 1, p.57-69.

Grosse, R. (1996). International Technology Transfer in Services. Journal of International Business Studies, v. 27, n. 4, p. 781-800.

Günsel, A. (2015). Research on effectiveness of technology transfer from a knowledge based perspective. Procedia - Social and Behavioral Sciences, v. 207, n. 2015, p. 777-785.

Hendrick, H. W. (1997). Macroergonomics: A proposed approach for use with anthropotechnology and ergonomic work analysis in effecting technology transfer. Travail Humain, 60(3), 255-272.

Ismail, M., Hamzah, S. R., \& Bebenroth, R. (2018). Differentiating knowledge transfer and technology transfer. European Journal Of Training And Development, v. 42, n. 9, p.611-628.

Karakosta, C., \& Psarras, J. (2009). Facilitating sustainable development in Chile: a survey of suitable energy technologies. International Journal of Sustainable Development \& World Ecology, v. 16, n. 5, p. 322-331.

Kirli, M. S., \& Fahrioğlu, M. (2018). Sustainable development of Turkey: Deployment of geothermal resources for carbon capture, utilization, and storage. Energy Sources, Part A: Recovery, Utilization, and Environmental Effects, v. 41, n. 14, p.1739- 1751.
Li-Hua, R. (2006). Examining the appropriateness and effectiveness of technology transfer in China. Journal of Technology Management in China, v. 1, n. 2, p. 208-223.

Lin, W. B. (2003). Technology Transfer as Technological Learning: A Source of Competitive Advantage for Firms with limited R \& D Resources. R \& D Management, v. 33, n. 3, p. 327-341.

Maskus, K. E. (2003). Encouraging International Technology Transfer. Intellectual Property Rights and Sustainable Development. ICTSD, UNCAD.

Mulamula, G., \& Amadi-Echendu, J. (2017). An examination of the potential links between ICT technology transfer and sustainable development. International Journal of Technology Management \& Sustainable Development, v. 16, n. 2, p. 119-139.

OECD. The measurement of scientific and technical activities: proposed standard method of compiling and interpreting technology balance of payments data (TBP Manual). Paris: OECD Publications, 1990. Disponível em: < https://search.oecd.org/sti/ inno/2347115.p

Pagani, R.N., Kovaleski, J.L., \& Resende, L.M. (2017). Tics na composição da methodi ordinatio: construção de portfólio bibliográfico sobre modelos de Transferência de Tecnologia. Ciência da Informação, v. 46, n. 2.

Pagani, R.N., Kovaleski, J.L., \& Resende, L.M. (2015). Methodi Ordinatio: a proposed methodology to select and rank relevant scientific papers encompassing the impact factor, number of citation, and year of publication, Scientometrics, v. 105, n. 3, p. 2109-2135.

Pagani, R. N., Zammar, G., Kovaleski, J. L., \& Resende, L. M. (2016). Technology transfer models: typology and a generic model. International Journal of Technology Transfer and commercialisation, v. 14, n. 1, p. 20.

Papaconstantinou, G.; Sakurai, N.; \& Wyckoff, A. (1998). Domestic and international product-embodied R\&D diffusion. Research Policy, 27(3), 301-314. doi:10.1016/s0048-7333(98)00044-4

Poizat, G., Durand, M., \& Theureau, J. (2016). The challenges of activity analysis for training objectives. TRavail Humain, 79(3), 233-258. https://doi.org/10.3917/th.793.0233

Reddy, N. M., \& Zhao, L. (1990). International technology transfer: A review. Research Policy, v. 19, n. 4, p. 285-307.

Rogers, E. M., Takegami, S., \& Yin, J. (2001). Lessons learned about technology transfer. Technovation, v. 21, n. 4, p.253-261.

Salahaldeen A. (1995). Developing countries and technology transfer, Int. J. of Technology Management. v. 10, n. 7-8, p.704-713. 
Shao, G., Li, F., \& Tang, L. (2011). Multidisciplinary perspectives on sustainable development. International Journal of Sustainable Development \& World Ecology, v. 18, n. 3, p. 187-189.

Souder, W. M. E., Nashar, A. S., \& Padmanabhan, V. (1990). A guide to the best technology-transfer practices. The Journal of Technology Transfer, v. 15, n. 1-2, p.5-16.

Sousa, A. A., \& Proença, R. P. (2005). The management of nutritional care in hospitals: comparative study Brazil-France [La gestion des soins nutritionnels dans le secteur hospitalier: une étude comparative Brésil-France.]. Recherche En Soins Infirmiers, (83), 28-33.

UN. Promote Sustainable Development. (2020). Retrieved $17 \mathrm{Au}-$ gust 2020, from https://www.un.org/en/sections/what-we-do/promote-sustainable-development/index.html

Wang, C. L. (2017). No-self, natural sustainability and education for sustainable development. Educational Philosophy and Theory, v. 49, n. 5 , p. $550-561$.

WCED (World Commission on Environment and Development). Our common future. Oxford: Oxford University Press, 1987.

Winebrake, J. (1992). A study of technology-transfer mechanisms for federally funded R\&D. The Journal Of Technology Transfer, 17(4), 54-61. doi: 10.1007/bf02172612
Wisner, A. (1995). The etienne grandjean memorial lecture situated cognition and action: Implications for ergonomic work analysis and anthropotechnology. Ergonomics, 38(8), 1542-1557. https://doi. org/10.1080/00140139508925209

Wisner, A. (2004). 7. Towards an anthropotechnology. X. A new activity for the united nations in the service of economic development: specifying requirements for technology transfers in given geographical and anthropological locations. Advances in Human Performance and Cognitive Engineering Research, 4, 215-221. https://doi. org/10.1016/S1479-3601(03)04007-4

Wisner, A. (1992). LAAnthropotechnologie. Estudos avançados, v. 6 (16).

Wisner, A. (1994). « La cognition et l'action situées : conséquences pour l'analyse ergonomique du travail et l'anthropotechnologie », Communication au congrès de l'IEA, rééditée in A. Wisner, Réflexions sur l'ergonomie (1962-1995), Toulouse, Octarès.

Yoon, W, \& Han, S. (2017). Does the potential for developing new technology lead to successful technology transfer commercialisation? The case of public R\&D outputs in Korea. International Journal Of Management Practice, v. 10, n. 1, p.93.

Yoon, W., \& Hyun, E. (2009). How relevant and useful is the concept of national systems of innovation? Journal of Technology Management \& Innovation, v. 4, n. 3, p.1-13. 
APPENDIX

Table 5. Final portfolio.

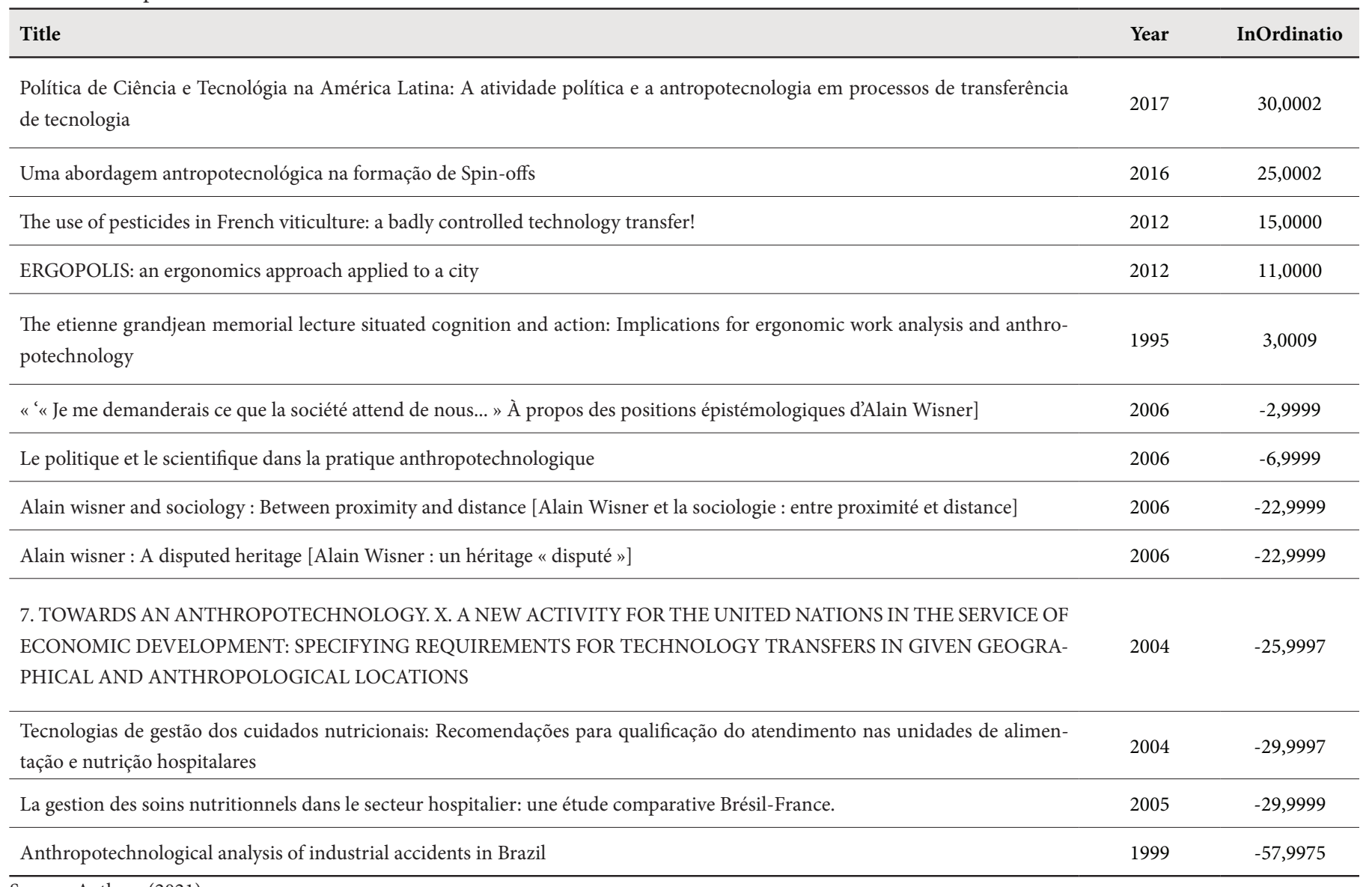

Source: Authors (2021) 
